\title{
Macrophage complexity in human atherosclerosis
}

Citation for published version (APA):

Biessen, E. A. L., \& Wouters, K. (2017). Macrophage complexity in human atherosclerosis: opportunities for treatment? Current Opinion in Lipidology, 28(5), 419-426.

https://doi.org/10.1097/MOL.0000000000000447

Document status and date:

Published: 01/10/2017

DOI:

10.1097/MOL.0000000000000447

Document Version:

Publisher's PDF, also known as Version of record

Document license:

Taverne

Please check the document version of this publication:

- A submitted manuscript is the version of the article upon submission and before peer-review. There can be important differences between the submitted version and the official published version of record.

People interested in the research are advised to contact the author for the final version of the publication, or visit the DOI to the publisher's website.

- The final author version and the galley proof are versions of the publication after peer review.

- The final published version features the final layout of the paper including the volume, issue and page numbers.

Link to publication

\footnotetext{
General rights rights.

- You may freely distribute the URL identifying the publication in the public portal. please follow below link for the End User Agreement:

www.umlib.nl/taverne-license

Take down policy

If you believe that this document breaches copyright please contact us at:

repository@maastrichtuniversity.nl

providing details and we will investigate your claim.
}

Copyright and moral rights for the publications made accessible in the public portal are retained by the authors and/or other copyright owners and it is a condition of accessing publications that users recognise and abide by the legal requirements associated with these

- Users may download and print one copy of any publication from the public portal for the purpose of private study or research.

- You may not further distribute the material or use it for any profit-making activity or commercial gain

If the publication is distributed under the terms of Article $25 \mathrm{fa}$ of the Dutch Copyright Act, indicated by the "Taverne" license above, 


\title{
Macrophage complexity in human atherosclerosis: opportunities for treatment?
}

\author{
Erik A.L. Biessen ${ }^{\mathrm{a}, \mathrm{c}}$ and Kristiaan Wouters ${ }^{\mathrm{b}}$
}

\begin{abstract}
Purpose of review
The pivotal role of macrophages in experimental atherosclerosis is firmly established, but their contribution to human disease is less well defined. In this review we have outlined the current insights on macrophage phenotypes and their presumed precursors, monocytes, in clinical atherosclerosis, and their association with disease progression. Moreover, we will assess major clinical modifiers of macrophage-mediated plaque inflammation and define the outstanding questions for further study.

\section{Recent findings}

Our survey indicates that macrophage accumulation and status in human plaques are linked with lesion progression and destabilization as well as with symptomatic coronary artery disease. Likewise, levels of their precursors, circulating monocytes were repeatedly seen to associate with atherosclerosis and to predict clinical outcome. Furthermore, the presence and phenotype of both macrophages and monocytes appears to be responsive to the traditional risk factors of atherosclerosis, including hypercholesterolemia, hypertension, and type 2 diabetes, and to treatment thereof, with clear repercussions on disease development.
\end{abstract}

\begin{abstract}
Summary
Although plaque macrophages and their precursor cells do represent attractive targets for treating cardiovascular diseases, this therapeutic avenue requires much deeper understanding of the complexity of macrophage biology in human atherosclerosis than available at present.
\end{abstract}

\section{Keywords}

arteriosclerosis, innate immunity, macrophage, monocytes, polarization, rupture

\section{INTRODUCTION}

Ischemic heart diseases (IHDs) are a leading death cause worldwide [1], despite major advances in diagnosis and - mostly preventive - treatment of known risk factors, such as dyslipidemia, type 2 diabetes, hypertension, and hypercoagulation. Inflammation is increasingly viewed as a causal process in IHD pathophysiology, affecting atherosclerotic lesion progression and postischemic responses in heart, brain, or kidney tissue. Macrophages are recognized as key mediators in IHD and related inflammation, primarily owing to their abundant presence in human ruptured plaque and based on numerous experimental studies in mouse models of disease [2"'].

Although the role of macrophages in preclinical models of disease has been amply documented, their direct contribution to human disease is much less developed. With recent major breakthroughs in our understanding of macrophage biology, heterogeneity, and function under homeostatic but also chronic inflammatory conditions, the evaluation of their relevance for and extrapolation of these findings to the clinical situation of human atherosclerosis is gradually emerging.

The present review aims to present an overview of the current insights on the presence and status of macrophages and their presumed precursors, monocytes, in clinical atherosclerosis, and their association with disease progression. Moreover, we will review the major clinical modifiers of macrophage-dependent plaque inflammation and will define the outstanding questions for further study.

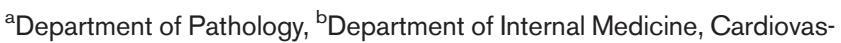
cular Research Institute Maastricht, Maastricht University, Maastricht, the Netherlands and Institute for Molecular Cardiovascular Research (IMCAR), University Hospital RWTH, Aachen, Aachen, Germany

Correspondence to Erik A.L. Biessen, Department of Pathology, Cardiovascular Research Institute Maastricht, Maastricht University, P. Debyelaan 25, 6229 HX Maastricht, the Netherlands. Tel: +31 43 3874635; fax: +31 43 3874635; e-mail: erik.biessen@mumc.nl

Curr Opin Lipidol 2017, 28:419-426

DOI:10.1097/MOL.0000000000000447 


\section{KEY POINTS}

- Human plaque harbors a broad spectrum of macrophage phenotypes, at which M1 polarization seems to be associated with plaque progression and instability.

- Circulating intermediate monocyte numbers are linked to cardiovascular outcome.

- Therapies against known risk factors of atherosclerosis potentially impact plaque macrophage phenotype and activity.

\section{Monocytes and macrophages in human atherosclerosis: current status}

Apart from their role in infection macrophages exert many functions to maintain tissue homeostasis, like clearance of senescent erythrocytes or apoptotic cells [3]. Consequently, macrophages react upon different environmental cues. Exemplary of this capability is the oversimplified classification of macrophages into classically activated macrophages (M1) and immune-modulatory alternatively activated macrophages (M2) [4], representing extreme phenotypes of multiple activation states [3]. Apart from M1 and M2 macrophages, thought to be proatherogenic and atheroprotective respectively, other subtypes have been described, like M2a, M2b, M2c, and M2d (reviewed in [5]). In the context of atherosclerosis, different plaque-specific signals generate several macrophage phenotypes, at lease in vitro, like Mhem macrophages activated by heme $[6,7], \mathrm{M} h b$ macrophages stimulated by hemoglobin [8], M4 macrophages induced by CXCL4 [9], and Mox macrophages after treatment of murine macrophages with oxidized phospholipids [10] (reviewed in $\left.\left[11^{"-}\right]\right)$. This emperical inflation-prone conception of macrophage polarization has recently been challenged by Xue et al. [12"'] proposing a new transcriptome-based model for macrophage phenotypic adaptation.

Until now, most efforts to define the macrophage phenotype in atherosclerosis have applied the M1/M2 classification scheme. Brand et al. [13] were the first to show prominent nuclear factor- $\kappa \mathrm{B}$ (NF-кB) activity in human plaque macrophages, hinting to a M1 polarized phenotype. Vulnerable plaque morphology correlated with $\mathrm{COX}^{+}$(M1) and MMP14+ macrophage presence (foam cells), whereas it was inversely associated with CD206 ${ }^{+}$ (M2) [14]. In slight contrast to this study, Stöger et al. failed to demonstrate a global predominance of M1 over M2 macrophages in vulnerable plaque. Nevertheless, M1 macrophage marker staining mainly confined to rupture-prone shoulder regions of the plaque, whereas M2 markers were present in vascular adventitial tissue [15]. This distribution relates M1 macrophages to worse cardiovascular prognosis. Table 1 provides an overview of studies linking human plaque macrophages with clinical outcome. Total plaque macrophage burden, defined by CD68-positive staining, associates with increased risk of stroke [16] and platelet reactivity [17], whereas associations with stenosis were less clear $[18,19]$.

Table 1. Summary of studies linking human plaque macrophage phenotype with clinical outcome of cardiovascular diseases

\begin{tabular}{|c|c|c|c|c|c|}
\hline First author & Year & Subset & Outcome & $n$ & Reference \\
\hline Hellings et al. & 2008 & $\mathrm{CD} 68^{+}$macrophages & Restenosis $\downarrow$ & 500 & [19] \\
\hline Hellings et al. & 2010 & $\mathrm{CD} 8^{+}$macrophages & $=$Vascular outcome & 818 & {$[20]$} \\
\hline Scholtes et al. & 2012 & MMP-12 producing macrophages ${ }^{a}$ & $C V$ events and stroke $\uparrow$ & 236 & {$[22]$} \\
\hline Medbury et al. & 2013 & $\begin{array}{l}\mathrm{CD}^{2} 8^{+}, \mathrm{CD}^{+} 4^{+}, \mathrm{CD} 86^{+} \text {cells }(\mathrm{M} 1) \\
\mathrm{CD} 163^{+} \text {and } \mathrm{CD}^{2} 06^{+} \text {cells }(\mathrm{M} 2)\end{array}$ & $\begin{array}{l}\text { Fibrotic cap thickness } \downarrow \\
=\text { Fibrotic cap thickness }\end{array}$ & 20 & {$[21]$} \\
\hline Lee et al. & 2013 & $\begin{array}{l}\text { CD68 }{ }^{+} \mathrm{cd} 11 \mathrm{c}^{+} \text {macrophage content } \\
\mathrm{CD} 68^{+} \mathrm{cd} 206^{+} \text {macrophage content }\end{array}$ & $\begin{array}{l}\uparrow \ln \mathrm{AMI} \\
=\ln \mathrm{AMI}\end{array}$ & 52 vs. 32 & {$[23]$} \\
\hline Cho et al. & 2013 & $\mathrm{CD} 68^{+} \mathrm{cd} 11 \mathrm{c}^{+}$macrophage content & $\uparrow \ln$ AMl & 31 vs. 34 & [24] \\
\hline Rutten et al. & 2014 & $\mathrm{CD} 68^{+}$macrophages & Platelet reactivity $\uparrow$ & 91 & {$[17]$} \\
\hline Howard et al. & 2015 & $\mathrm{CD} 68^{+}$macrophages & Stroke risk $\uparrow$ & 1640 & [16] \\
\hline Merckelbach et al. & 2016 & $\mathrm{CD} 68^{+}$macrophages & $=$Stenosis & 760 & [18] \\
\hline de Gaetano et al. & 2016 & $\begin{array}{l}\text { M1 gene expression }{ }^{b} \\
\text { M2 gene expression }\end{array}$ & $\begin{array}{l}\uparrow \text { In symptomatic CAD } \\
\downarrow \text { In symptomatic CAD }\end{array}$ & 80 & {$\left[25^{-}\right]$} \\
\hline
\end{tabular}

aMMP12/CD68 ratio.

${ }^{\mathrm{b}} \mathrm{TNF}, \mathrm{IL}-6, \mathrm{IL}-8$.

${ }^{\mathrm{C} C C L} 22, \mathrm{IL}-10, \mathrm{IL}-13, \mathrm{CD} 163, \mathrm{CD} 2016$ 
Although total plaque macrophages did not predict vascular outcome in a study including 818 endarterectomy patients [20], further classification of macrophages based on M1 and M2 markers does show clinical relevance of macrophage burden in the plaque (Table 1). M1 markers are associated with decreased fibrotic cap thickness [21] and MMP12producing plaque macrophages predict cardiovascular events and stroke incidence [22]. Moreover, although M2 plaque macrophages are not increased in plaques of acute myocardial infarction patients [23], M1 macrophages are more abundant in plaque material of infarction patients and of coronary artery disease patients [23,24,25"].

Much of the supportive data on plaque-specific macrophage polarization is based on in vitro experiments using single stimuli. However, the plaque harbors gradients of multiple stimuli, which, to complicate matters even more, depend on the plaque progression status [2"']. Therefore, it is difficult to define separate plaque macrophage subsets. Despite existing data on plaque macrophages and clinical outcome, a recent study failed to identify differences in M1 and M2 macrophages in early, late, unstable, or ruptured lesions, underlining that current classifications of plaque macrophages are too simplistic $\left[2^{\prime \prime}\right]$. Rather than looking for polarized macrophages in the plaque, a more sensible approach may be to define the inflammatory phenotype of macrophages that are associated with a specific plaque region. For example, a recent study focused on macrophages found in calcified areas of the plaque and showed that they share many features with M2 macrophages [27].

Besides macrophages, also their precursor cells, monocytes, display heterogeneity. Human monocytes are subdivided based on their expression of CD14 and CD16. Classical monocytes express high levels of CD14 and no CD16 (CD14 $\left.{ }^{++} \mathrm{CD} 16^{-}\right)$ $\mathrm{CD} 16^{-}$) and compromise the majority of total monocytes whereas nonclassical monocytes express CD16 and intermediate levels of CD14 (CD14 ${ }^{+}$ $\left.\mathrm{CD} 16^{++}\right)$. In addition, humans display also intermediate monocytes $\left(\mathrm{CD} 14^{++} \mathrm{CD} 16^{+}\right)$[28]. Experimental data from murine myocardial infarction models [29] suggest that M1 macrophages mainly originate from extravasated classical monocytes, whereas nonclassical monocytes share more features with M2 cells, albeit that conclusive evidence is currently lacking [28]. Moreover, the dynamics of postinfarct inflammation may not completely reflect the chronic low-grade inflammation that is typical of atherosclerosis, especially in humans. As can be appreciated from Table 2, most studies find positive relations between intermediate monocytes and cardiovascular outcome [30-41].

Based on the studies, summarized in Tables 1 and 2 , both cardiovascular events and atherosclerotic plaque thinning tend to be associated with M1 polarized plaque macrophages and circulating intermediate CD14(++)CD16(+) monocytes. This intermediate subset adhered much more avidly to endothelium than their classical and nonclassical antipodes, and this effect capacity augmented for monocytes from AMI patients, possibly owing to triglyceride induced CD11c integrin expression and clustering [36]. It is therefore tempting to speculate that, in addition to intraplaque cues, recruitment of intermediate monocytes contributes to a detrimental plaque macrophage signature, worsening clinical outcome. However, no mechanistic evidence is available to validate this hypothesis.

Table 2. Summary of studies linking circulating monocyte subsets with clinical outcome of cardiovascular diseases

\begin{tabular}{|c|c|c|c|c|c|}
\hline First author & Year & Subset & Outcome & n & Reference \\
\hline Heine & 2008 & Intermediate monocytes & Predict CV events & 94 & [39] \\
\hline Imanishi & 2010 & CDI6+ monocytes ${ }^{a}$ & Inverse association with fibrous cap thickness & 40 & [37] \\
\hline Ikejima & 2010 & $\mathrm{CD} 6^{+}$monocytes $^{\mathrm{a}}$ & Association with plaque ruptures & 27 vs. 19 & [38] \\
\hline Rogacev et al. & 2010 & $\mathrm{CD} 6^{+}$monocytes $^{\mathrm{a}}$ & $\uparrow \mathrm{IMT}$ & 622 & [33] \\
\hline Poitou et al. & 2011 & Intermediate monocytes & Correlate with IMT changes during weight loss & 36 & [30] \\
\hline Rogacev et al. & 2011 & Intermediate monocytes & Longitudinal Association with cardiovascular events & 119 & [31] \\
\hline Rogacev et al. & 2012 & Intermediate monocytes & Cardiovascular Events prediction & 951 & [32] \\
\hline Berg et al. & 2012 & Classical monocytes & Cardiovascular events prediction & 659 & {$[41]$} \\
\hline Foster et al. & 2013 & Intermediate monocytes & $\uparrow$ vcam-mediated adhesion & 9 vs. 13 & [36] \\
\hline Zeng et al. & 2014 & Intermediate monocytes & Association with unstable angina & 95 vs. 30 & [35] \\
\hline Winchester et al. & 2016 & Intermediate monocytes & Correlate with coronary artery calcification & 72 & {$[34]$} \\
\hline Wildgruber et al. & 2016 & Intermediate monocytes & Restenosis prediction & 67 & {$[40]$} \\
\hline
\end{tabular}

Intermediate and nonclassical. 
Although human intermediate monocytes do not have a murine counterpart, they do share features with mouse classical monocytes, including high expression of CCR2, CCR5, and CX3CR1 [28,42]. Strong experimental evidence exists that Ly-6C ${ }^{\text {hi }}$ classical murine monocytes preferentially accumulate in the vessel wall depending on CX3CR1, CCR2, and CCR5 $[43,44]$, providing at least partial back up for this hypothesis. In line, senescent human intermediate monocytes increase their inflammatory phenotype and adhesive ability, possibly explaining the increased risk for cardiovascular diseases (CVD) with age [45].

\section{Impact of CVD risk factors and cognate drug interventions on plaque macrophage status}

Because of their high plastic capacity to adapt to the range of stimuli contained in the local microenvironment, plaque macrophages are likely responsive to metabolic risk factors and medication targeting these factors, with potential repercussions for disease progression. Over the past decade, this notion has been supported by several histopathological studies. Below we have outlined these phenotypic changes for the major risk factors and treatment thereof.

\section{Dyslipidemia}

This risk factor is a major modifier of monocyte and macrophage phenotype. A recent study by Stroes et al. [46] demonstrated lipid accumulation in circulating monocytes of familial hypercholesterolemia (FH) patients. This accumulation was accompanied by elevated CCR2 expression and ex-vivo chemotaxis in classical monocytes, suggesting augmented plaque invasion. These effects could be reversed by PCSK9 neutralizing therapy (alurcimab) to reduce plasma LDL levels. Although lipid accumulation by circulating monocytes was also observed in an FH mouse model (LDLR ${ }^{-1-}$ ), this was accompanied by defective migratory responses [47], without compromising endothelial adhesion and transmigration.

Lipid accumulation is also hallmarking the atherosclerotic macrophage. Sterols, fatty acids terpenes, and lysolipids can all interfere with macrophage functions by interacting with nuclear receptor family members, that are critical in macrophage homeostasis (e.g. FXR, LXR, ROR, N4Rs, and PPARs), as also outlined in numerous studies (reviewed in [48]). Apart from direct signaling, excessive cholesterol loading can induce endoplasmic reticulum stress and inflammasome activation, both acting proinflammatory. However, lipid laden foam cells were reported to have suppressed proinflammatory [49] or even profibrotic activity [50], both in vitro and in vivo, which was attributed to LXR activation by intracellular desmosterol.

Obviously, pharmacological correction of blood cholesterol levels, by statins, will have deep impact on plaque macrophages. Already in 2002, atorvastatin treatment was reported to change the inflammatory/thrombotic phenotype of carotid artery plaques [51] and these findings have been corroborated in several studies hereafter. As shown by Pasterkamp et al. [52], statin use is associated with smaller, more stable plaques (fewer macrophages, thrombi, calcification nodules). Even 3-month statin treatment of stroke patients dose-dependently could lower plaque macrophage content [53]. In keeping, the Fuster group reported sharply decreased atheroma formation, macrophage content, neoangiogenesis, and hemorrhage after statin treatment [54]. Carotid endarterectomy patients on atorvastatin therapy contained more $\mathrm{CD}^{+} 8^{+}$ macrophages, but paradoxically, this was associated with quenched rather than augmented intraplaque protease activity, Interleukin-6 expression, and enhanced fibrosis [55]. Whether statins effect these beneficial changes solely by their lipid lowering activity is unclear. Although statin effects have been reported to be LDL-C dependent [53], LDL independent modes have been proposed as well. Statins can target plaque inflammation and stabilize plaque, among others by inducing plaque galectin 3 expression [56], inhibiting the COX-2/mPGES axis [57] or by inducing PPARy [58], all known to drive macrophage polarization toward an anti-inflammatory phenotype. An in-depth study of lipiddependent and lipid-independent mechanisms for statin effects on plaque macrophages are however still awaited.

\section{Hypertension}

A major risk factor for CVD, hypertension is routinely targeted in high-risk patients, by blocking angiotensin, adrenergic, or calcium channel signaling. Angiotensin-II signaling is reduced by angiotensin-I converting enzyme (ACE) or angiotensin II receptor 1A (AT1) receptor inhibition. Angiotensin therapy is expected to interfere with the activity of this subset for at least three reasons. First, carotid arteries contain detectable levels of ACE colocalizing with plaque inflammation [58]. Second, macrophages were seen to express key components of the angiotensin axis, including angiotensin II receptor type I (AT1) receptors. Finally, angiotensin II activation promotes lipid accumulation and migration, and shifts polarization towards the 
proinflammatory M1 phenotype [59]. Only a single study centered on the repercussions of angiotensin II-targeted therapy for human plaque macrophage status [60]: AT1 blockage (irbesartan) dampened COX-2/mPGES-1 dependent inflammation in plaque macrophages. Indeed, macrophage AT1 signaling induces cytokine and ROS production [60], and macrophage-specific AT1 deficiency increased phagocytotic capacity and their resistance to apoptosis. Hence, AT1 blocking has an M2 polarizing effect, as was also observed in murine renal-injury induced atherosclerosis [59].

Signaling of macrophage adrenergic receptors, a second important target in antihypertensive therapy, also affects their inflammatory response. $\beta$-Adrenergic receptor activation favors M2 polarization, while suppressing M1 gene programs; conversely $\alpha$-adrenergic signaling induces pro-inflammatory gene expression, an effect considered to be detrimental [61"]. Although no human histology data are available to confirm this notion, this may plead in favor of the use of combined $\alpha / \beta$ instead of only $\beta$-selective adrenergic blockage. Regarding calcium channel blockers, a third major hypertension therapy target, data are inconsistent, although their use has been linked with increased carotid plaque progression in asymptomatic patients ( $n=900$ carotids) [62].

\section{Type 2 diabetes}

Although elevated glucose levels in patients with type 2 diabetes (T2D) may impact plaque macrophage function T2D status did not impact plaque macrophage content or lipid and SMC content in a medium-sized cohort [63]. Accordingly, despite a shift toward a more calcified plaque phenotype and higher a risk of future cardiovascular events in patients with T2D, Pasterkamp et al. [64] observed equivalent plaque macrophage content compared with plaques from patients without T2D. Plaque macrophages of patients with diabetes showed evidence of metabolic adaptations in glucose flux (as judged from the induced aldose reductase expression), which could potentially augment intracellular ROS and cytokine production [65"]. Moreover, hyperglycemia was shown to blunt M2 polarization, skewing macrophage phenotype toward a proinflammatory M1 phenotype in experimental atherosclerosis [66]. However, it is unclear whether, rather than total macrophage content, macrophage polarization status is related to T2D.

Conversely, numerous studies documented that lowering glucose levels with metformin has significant antiinflammatory activity. Metformin reduced maximal, not mean intimal stenosis (cIMT) in (type 1 ) diabetics [67"-], whereas in patients without diabetes it failed to reduce mean cIMT, despite lowering HBA1c and glucose levels [67"']. DPP-4, another preferred target in diabetic therapy, is downregulated during monocyte-macrophage differentiation and only scarcely expressed in plaques, by microvascular endothelium [67"']. Its inhibition was reported to act immune-suppressive, potentially by dampening NF- $\kappa \mathrm{B}$ and AP-1 transcriptional activity [68"]. Based on these data and its atheroprotective activity in a diabetic mouse model of atherosclerosis, favorable effects of DPP4 inhibition on plaque macrophages are to be expected. However, histological proof is awaited.

\section{Outstanding questions}

From the above overview one may conclude that our understanding of human macrophages and their precursors in atherosclerosis-related IHD is limited, and most studies are of descriptive nature. A first open question involves the plaque macrophage origin; whether macrophages are derived from invading monocytes [2"] or from expanding resident macrophages (as proposed in recent experimental studies [69"']). Plaque macrophage origin will have major implications for the effectiveness of chemotaxis-targeting therapies. Currently, little is known about the quantitative role of proliferating resident macrophage on plaque progression compared to recruitment of circulating monocytes, and in particular of intermediate monocytes. In addition, vascular smooth muscle cells also have been described to transdifferentiate into macrophages, contributing to plaque macrophage burden [70]. The current literature (Tables 1 and 2) suggests that circulating intermediate monocytes are linked to pro-atherogenic macrophage subsets in human plaque. To delineate such a relationship, there is a need for studies that simultaneously assess plaque macrophage phenotype and circulating monocyte subsets in an individual patient (as we recently showed for adipose tissue macrophages [71"]). To unravel the developmental origin of plaque macrophages and their contribution to plaque growth and phenotype, we are most likely confined to murine models.

A second challenge concerns macrophage heterogeneity. Although this has been well established for many tissues in healthy and diseased situations, hardly any quantitative data on spatiotemporal dynamics and impact of environmental factors (such as diet/medication) on macrophage subset profiles are available for human atherosclerosis [26"]. Given the high functional diversity of macrophage subsets, a better definition of macrophages species most correlated with an adverse disease progression will 
be indispensable for tailored intervention or imaging measures. At present, the conventional cell separation techniques, such as fluorescence-activated cell sorting, fall short to discriminate macrophage subsets in human plaque. This is, among others, due to the intrinsically high autofluorescence, the large bandwidth in size and density of plaque macrophages, to the high plaque content of cell debris, to selection bias of current markers, and to the need of aggressive tissue dissolution strategies. The use of mass cytometry or single cell sequencing techniques could at least partly circumvent this setback.

A third challenge relates to the macrophage microenvironment. As described above, macrophages adapt to their local (and indirectly to the global) context. Identification of the culprit components in the plaque microenvironment, which drive adverse macrophage functions in disease progression, will obviously provide unprecedented opportunities to steer or reinstruct detrimental macrophage populations in plaque by drug or dietary intervention. MRI and ex-vivo studies on tissue biopsies, could pave the way to such identification.

\section{CONCLUSION}

As outlined in this review, numerous studies have highlighted the importance of macrophages and their precursor monocytes in atherosclerosis related IHD. Monocytes and in particular intermediate monocytes were correlated with disease progression and incidence of clinical events. For macrophages, data are rather inconsistent, implying that macrophage location seems more relevant than mere content. Interestingly, the more widespread use of stringent medication, such as statins, antihypertensives, and antidiabetics, has impacted macrophage status and numbers in plaques, and this might have been instrumental in the gradual shift from rupture prone plaque phenotype toward more fibrotic and calcified, but also erosion-prone plaques as Pasterkamp et al. [46] have shown.

The present review also underpins the relevance of a better definition of the direct microenvironment and phenotype of macrophages, as such information will be pivotal in developing a macrophage-targeted intervention strategies that are effective at all stages of disease, and do not compromise beneficial macrophage functions in injury repair or host defense.

\section{Acknowledgements}

None.

\section{Financial support and sponsorship}

EB: ITN-EJD Evolution; H2020-MSCA-ITN-2015 (grant no 675111) and ITN-EJD-INTRICARE; H2020-MSCAITN-EJD 2016 (grant no 722609).

KW: Netherlands Heart Foundation (2013T143)

\section{Conflicts of interest}

There are no conflicts of interest.

\section{REFERENCES AND RECOMMENDED}

\section{READING}

Papers of particular interest, published within the annual period of review, have been highlighted as:

- of special interest

- of outstanding interest

1. Lloyd-Jones DM. Cardiovascular risk prediction: basic concepts, current status, and future directions. Circulation 2010; 121:1768-1777.

2. Tabas I, Bornfeldt KE. Macrophage phenotype and function in different stages - of atherosclerosis. Circ Res 2016; 118:653-667.

This review provides good insight in the different stimuli that are pressent in the atherosclerotic plaque and can influence resident macrophages.

3. Mosser DM, Edwards JP. Exploring the full spectrum of macrophage activation. Nat Rev Immunol 2008; 8:958-969.

4. Gordon S. Alternative activation of macrophages. Nat Rev Immunol 2003; 3:23-35.

5. Colin S, Chinetti-Gbaguidi G, Staels B. Macrophage phenotypes in atherosclerosis. Immunol Rev 2014; 262:153-166.

6. Boyle JJ, Johns M, Kampfer T, et al. Activating transcription factor 1 directs Mhem atheroprotective macrophages through coordinated iron handling and foam cell protection. Circ Res 2012; 110:20-33.

7. Boyle JJ, Harrington HA, Piper E, et al. Coronary intraplaque hemorrhage evokes a novel atheroprotective macrophage phenotype. Am J Pathol 2009; 174:1097-1108.

8. Finn AV, Nakano M, Polavarapu R, et al. Hemoglobin directs macrophage differentiation and prevents foam cell formation in human atherosclerotic plaques. J Am Coll Cardiol 2012; 59:166-177.

9. Gleissner CA, Shaked I, Erbel C, et al. CXCL4 downregulates the atheroprotective hemoglobin receptor CD163 in human macrophages. Circ Res 2010; 106:203-211.

10. Kadl A, Meher AK, Sharma PR, et al. Identification of a novel macrophage phenotype that develops in response to atherogenic phospholipids via Nrf2. Circ Res 2010; 107:737-746.

11. Chinetti-Gbaguidi $G$, Colin $S$, Staels $B$. Macrophage subsets in atherosclero-

- sis. Nat Rev Cardiol 2015; 12:10-17.

The present review provides a clear overview of the different macrophage subsets associated with atherosclerosis.

12. Xue J, Schmidt SV, Sander J, et al. Transcriptome-based network analysis

- reveals a spectrum model of human macrophage activation. Immunity 2014; 40:274-288.

This seminal paper provides a transcriptomics based classification scheme for macrophage phenotypic adaptation to replace the rigid dichotomous M1/M2 polarization model.

13. Brand K, Page S, Rogler G, et al. Activated transcription factor nuclear factorkappa B is present in the atherosclerotic lesion. J Clin Invest 1996; 97: 1715-1722.

14. Johnson JL, Jenkins NP, Huang WC, et al. Relationship of MMP-14 and TIMP3 expression with macrophage activation and human atherosclerotic plaque vulnerability. Mediators Inflamm 2014; 2014:276457.

15. Stoger JL, Gijbels MJ, van der Velden S, et al. Distribution of macrophage polarization markers in human atherosclerosis. Atherosclerosis 2012; 225: $461-468$.

16. Howard DP, van Lammeren GW, Rothwell PM, et al. Symptomatic carotid atherosclerotic disease: correlations between plaque composition and ipsilateral stroke risk. Stroke 2015; 46:182-189.

17. Rutten $B$, Tersteeg $C$, Vrijenhoek JE, et al. Increased platelet reactivity is associated with circulating platelet-monocyte complexes and macrophages in human atherosclerotic plaques. PLoS One 2014; 9:e105019.

18. Merckelbach $S$, Leunissen $T$, Vrijenhoek J, et al. Clinical risk factors and plaque characteristics associated with new development of contralateral stenosis in patients undergoing carotid endarterectomy. Cerebrovasc Dis 2016; 42:122-130.

19. Hellings WE, Moll FL, De Vries JP, et al. Atherosclerotic plaque composition and occurrence of restenosis after carotid endarterectomy. JAMA 2008; 299:547-554 
20. Hellings WE, Peeters W, Moll FL, et al. Composition of carotid atherosclerotic plaque is associated with cardiovascular outcome: a prognostic study. Circulation 2010; 121:1941-1950.

21. Medbury $\mathrm{HJ}$, James $\mathrm{V}, \mathrm{Ngo} \mathrm{J}$, et al. Differing association of macrophage subsets with atherosclerotic plaque stability. Int Angiol 2013; 32:74-84.

22. Scholtes VP, Johnson JL, Jenkins $\mathrm{N}$, et al. Carotid atherosclerotic plaque matrix metalloproteinase-12-positive macrophage subpopulation predicts adverse outcome after endarterectomy. J Am Heart Assoc 2012; $1: e 001040$.

23. Lee CW, Hwang I, Park CS, et al. Macrophage heterogeneity of culprit coronary plaques in patients with acute myocardial infarction or stable angina. Am J Clin Pathol 2013; 139:317-322.

24. Cho KY, Miyoshi $\mathrm{H}$, Kuroda $\mathrm{S}$, et al. The phenotype of infiltrating macrophages influences arteriosclerotic plaque vulnerability in the carotid artery. J Stroke Cerebrovasc Dis 2013; 22:910-918

25. de Gaetano M, Crean D, Barry M, Belton O. M1- and M2-type macrophage responses are predictive of adverse outcomes in human atherosclerosis. Front Immunol 2016; 7:275.

Interesting paper showing that gene and protein expression of M1 markers and Th1-associated cytokines are highly expressed in symptomatic human plaques.

26. van Dijk RA, Rijs $K$, Wezel $A$, et al. Systematic evaluation of the cellular innate

- immune response during the process of human atherosclerosis. J Am Heart Assoc 2016; 5:. doi: 10.1161/JAHA.115.002860, pii: e002860.

The present paper shows that M1 and M2 macrophage both are strongly associated with progressive and vulnerable atherosclerosis in humans, showing that the prevailing dogma of macrophage polarization is overly simplistic to describe human pathogenesis.

27. Chinetti-Gbaguidi G, Daoudi M, Rosa M, et al. Human alternative macrophages populate calcified areas of atherosclerotic lesions and display impaired RANKL-induced osteoclastic bone resorption activity. Circ Res 2017; 121:19-30.

28. Ghattas A, Griffiths $H R$, Devitt $A$, et al. Monocytes in coronary artery disease and atherosclerosis: where are we now? J Am Coll Cardiol 2013; 62: $1541-1551$.

29. Nahrendorf M, Swirski FK, Aikawa E, et al. The healing myocardium sequentially mobilizes two monocyte subsets with divergent and complementary functions. J Exp Med 2007; 204:3037-3047.

30. Poitou C, Dalmas E, Renovato $M$, et al. CD14dimCD16+ and CD14+CD16+ monocytes in obesity and during weight loss: relationships with fat mass and subclinical atherosclerosis. Arterioscler Thromb Vasc Biol $2011 ; 31: 2322-2330$.

31. Rogacev KS, Cremers B, Zawada AM, et al. CD14++CD16+ monocytes independently predict cardiovascular events: a cohort study of 951 patients referred for elective coronary angiography. J Am Coll Cardiol 2012; 60: $1512-1520$.

32. Rogacev KS, Seiler S, Zawada AM, et al. CD14++CD16+ monocytes and cardiovascular outcome in patients with chronic kidney disease. Eur Heart J $2011 ; 32: 84-92$

33. Rogacev KS, Ulrich C, Blomer L, et al. Monocyte heterogeneity in obesity and subclinical atherosclerosis. Eur Heart J 2010; 31:369-376.

34. Winchester R, Giles JT, Nativ S, et al. Association of elevations of specific T cell and monocyte subpopulations in rheumatoid arthritis with subclinical coronary artery atherosclerosis. Arthritis Rheumatol 2016; 68:92-102.

35. Zeng $\mathrm{S}$, Zhou $\mathrm{X}, \mathrm{Ge} \mathrm{L}$, et al. Monocyte subsets and monocyte-platelet aggregates in patients with unstable angina. J Thromb Thrombolysis 2014; 38:439-446.

36. Foster GA, Gower RM, Stanhope KL, et al. On-chip phenotypic analysis of inflammatory monocytes in atherogenesis and myocardial infarction. Proc Natl Acad Sci U S A 2013; 110:13944-13949.

37. Imanishi $\mathrm{T}$, Ikejima $\mathrm{H}, \mathrm{T}$ sujioka $\mathrm{H}$, et al. Association of monocyte subset counts with coronary fibrous cap thickness in patients with unstable angina pectoris. Atherosclerosis 2010; 212:628-635.

38. Ikejima $\mathrm{H}$, Imanishi $\mathrm{T}$, Tsujioka $\mathrm{H}$, et al. Upregulation of fractalkine and its receptor, CX3CR1, is associated with coronary plaque rupture in patients with unstable angina pectoris. Circ J 2010; 74:337-345.

39. Heine $\mathrm{GH}$, Ulrich $\mathrm{C}$, Seibert $\mathrm{E}$, et al. CD14(++)CD16+ monocytes but not total monocyte numbers predict cardiovascular events in dialysis patients. Kidney Int 2008; 73:622-629.

40. Wildgruber $M$, Czubba $M$, Aschenbrenner $T$, et al Increased intermediate CD14++CD16++ monocyte subset levels associate with restenosis after peripheral percutaneous transluminal angioplasty. Atherosclerosis 2016; 253:128-134.

41. Berg KE, Ljungcrantz I, Andersson L, et al. Elevated CD14++CD16- monocytes predict cardiovascular events. Circ Cardiovasc Genet 2012; 5: $122-131$

42. Mandl M, Schmitz S, Weber $C$, Hristov $M$. Characterization of the CD14++CD16+ monocyte population in human bone marrow. PLoS One 2014; 9:e112140.

43. Tacke $F$, Alvarez $D$, Kaplan $T J$, et al. Monocyte subsets differentially employ CCR2, CCR5, and CX3CR1 to accumulate within atherosclerotic plaques. J Clin Invest 2007; 117:185-194.

44. Swirski FK, Libby $\mathrm{P}$, Aikawa $\mathrm{E}$, et al. Ly-6Chi monocytes dominate hypercholesterolemia-associated monocytosis and give rise to macrophages in atheromata. J Clin Invest 2007; 117:195-205.
45. Merino A, Buendia P, Martin-Malo A, et al. Senescent CD14+CD16+ monocytes exhibit proinflammatory and proatherosclerotic activity. J Immunol 2011; 186:1809-1815.

46. Bernelot Moens SJ, Neele AE, Kroon J, et al. PCSK9 monoclonal antibodies reverse the pro-inflammatory profile of monocytes in familial hypercholesterolaemia. Eur Heart J 2017; 38:1584-1593.

47. Jackson WD, Weinrich TW, Woollard KJ. Very-low and low-density lipoproteins induce neutral lipid accumulation and impair migration in monocyte subsets. Sci Rep 2016; 6:20038.

48. Frieler RA, Ramnarayanan $S$, Mortensen RM. Nuclear receptor control of opposing macrophage phenotypes in cardiovascular disease. Front Biosci (Landmark Ed) 2012; 17:1917-1930.

49. Spann NJ, Garmire LX, McDonald JG, et al. Regulated accumulation of desmosterol integrates macrophage lipid metabolism and inflammatory responses. Cell 2012; 151:138-152.

50. Thomas AC, Eijgelaar WJ, Daemen MJ, Newby AC. Foam cell formation in vivo converts macrophages to a pro-fibrotic phenotype. PLoS One 2015; 10:e0128163.

51. Cortellaro M, Cofrancesco E, Arbustini E, et al. Atorvastatin and thrombogenicity of the carotid atherosclerotic plaque: the ATROCAP study. Thromb Haemost 2002; 88:41-47.

52. van Lammeren GW, den Ruijter HM, Vrijenhoek JE, et al. Time-dependent changes in atherosclerotic plaque composition in patients undergoing carotid surgery. Circulation 2014; 129:2269-2276.

53. Puato $M$, Faggin $E$, Rattazzi $M$, et al. Atorvastatin reduces macrophage accumulation in atherosclerotic plaques: a comparison of a nonstatin-based regimen in patients undergoing carotid endarterectomy. Stroke 2010; 41: 1163-1168.

54. Pucci $A$, Sheiban I, Formato $L$, et al. In vivo coronary plaque histology in patients with stable and acute coronary syndromes: relationships with hyperlipidemic status and statin treatment. Atherosclerosis 2007; 194: 189-195.

55. Verhoeven BA, Moll FL, Koekkoek JA, et al. Statin treatment is not associated with consistent alterations in inflammatory status of carotid atherosclerotic plaques: a retrospective study in 378 patients undergoing carotid endarterectomy. Stroke 2006; 37:2054-2060.

56. Kadoglou NP, Sfyroeras GS, Spathis A, et al. Galectin-3, carotid plaque vulnerability, and potential effects of statin therapy. Eur J Vasc Endovasc Surg 2015; 49:4-9.

57. Cipollone F, Fazia M, lezzi A, et al. Suppression of the functionally coupled cyclooxygenase-2/prostaglandin $\mathrm{E}$ synthase as a basis of simvastatindependent plaque stabilization in humans. Circulation 2003; 107: $1479-1485$.

58. Skoczynska A, Dobosz T, Poreba R, et al. The dependence of serum interleukin-6 level on PPAR-alpha polymorphism in men with coronary atherosclerosis. Eur J Intern Med 2005; 16:501-506.

59. Yamamoto S, Yancey PG, Zuo Y, et al. Macrophage polarization by angiotensin Il-type 1 receptor aggravates renal injury-acceleration of atherosclerosis. Arterioscler Thromb Vasc Biol 2011; 31:2856-2864.

60. Cipollone F, Fazia M, lezzi A, et al. Blockade of the angiotensin II type 1 receptor stabilizes atherosclerotic plaques in humans by inhibiting prostaglandin E2-dependent matrix metalloproteinase activity. Circulation 2004; 109:1482-1488.

61. Barnes MA, Carson MJ, Nair MG. Nontraditional cytokines: how catechola-

mines and adipokines influence macrophages in immunity, metabolism and the central nervous system. Cytokine 2015; 72:210-219.

Excellent review describing the effect of catecholamines on macrophage phenotype and function.

62. Conrad MF, Boulom V, Mukhopadhyay S, et al. Progression of asymptomatic carotid stenosis despite optimal medical therapy. J Vasc Surg 2013; 58: 128-135; e121.

63. Edsfeldt A, Goncalves I, Grufman $\mathrm{H}$, et al. Impaired fibrous repair: a possible contributor to atherosclerotic plaque vulnerability in patients with type II diabetes. Arterioscler Thromb Vasc Biol 2014; 34: 2143-2150.

64. van Haelst ST, Haitjema S, de Vries JP, et al. Patients with diabetes differ in atherosclerotic plaque characteristics and have worse clinical outcome after iliofemoral endarterectomy compared with patients without diabetes. J Vasc Surg 2017; 65:414-421; e415

65. Erbel C, Rupp G, Domschke G, et al. Differential regulation of aldose

reductase expression during macrophage polarization depends on hyperglycemia. Innate Immun 2016; 22:230-237.

This is one of few papers to address the potential relevance of immunometabolism in human plaque macrophages

66. Parathath S, Grauer L, Huang LS, et al. Diabetes adversely affects macrophages during atherosclerotic plaque regression in mice. Diabetes 2011; 60:1759-1769.

67. Petrie JR, Chaturvedi N, Ford I, et al. Cardiovascular and metabolic effects of

I. metformin in patients with type 1 diabetes (REMOVAL): a double-blind, randomised, placebo-controlled trial. Lancet Diabetes Endocrinol 2017. [Epub ahead of print]

This is the first study showing that metformin could diminish intima media thickness even without sustained effects on hyperglycemia. 
68. Shinjo T, Nakatsu $\mathrm{Y}$, Iwashita M, et al. DPP-IV inhibitor anagliptin exerts anti-

- inflammatory effects on macrophages, adipocytes, and mouse livers by suppressing NF-kappaB activation. Am J Physiol Endocrinol Metab 2015; 309:E214-223.

This paper describes direct anti-inflammatory effects of DPP-IV inhibitors via NF-кB.

69. Ginhoux F, Guilliams M. Tissue-resident macrophage ontogeny homeostasis. I. Immunity 2016; 44:439-449.

Important review on the recent discoveries on murine tissue macrophage origin and ontogeny.
70. Feil S, Fehrenbacher B, Lukowski R, et al. Transdifferentiation of vascular smooth muscle cells to macrophage-like cells during atherogenesis. Circ Res 2014; 115:662-667.

71. Wouters K, Gaens K, Bijnen M, et al. Circulating classical monocytes are

- associated with CD11c+ macrophages in human visceral adipose tissue. Sci Rep 2017; 7:42665.

This paper was the first to measure different imune cell populations in blood and both visceral and subcutaneous adipose tissue of lean and obese individuals, showing that M1 macrophages in visceral adipose tissue are associated with circulating classical monocytes. 